\title{
Intravenous ibandronate injections given every three months: a new treatment option to prevent bone loss in postmenopausal women
}

\author{
J A Stakkestad, L I Benevolenskaya, J J Stepan, A Skag, A Nordby, E Oefjord, \\ A Burdeska, I Jonkanski, P Mahoney, for the Ibandronate Intravenous Study Group
}

See end of article for authors' affiliations

Correspondence to: Dr J A Stakkestad, CECOR AS, Nygårdsveien 6, PO Box 1364, Gard 5507 Haugesund, Norway; jacobas@cecor.no

Accepted

3 February 2003

\begin{abstract}
Objective: To investigate the efficacy, safety, and dose response of three doses of ibandronate, given intermittently by intravenous (IV) injection every three months, in preventing postmenopausal osteoporosis.

Patients and methods: 629 postmenopausal women, categorised according to time since menopause and baseline lumbar spine (L1-4) bone mineral density (BMD), were enrolled into a multicentre, double blind, placebo controlled trial. They were randomly allocated to receive IV ibandronate $0.5 \mathrm{mg}, 1 \mathrm{mg}$ or $2 \mathrm{mg}$, or placebo every three months. All women received daily calcium supplementation.

Results: One year's treatment with intermittent IV ibandronate injections produced a dose dependent gain in mean (SD) lumbar spine BMD from baseline of $2.5(2.5) \%, 1.8(2.6) \%$, and $1.0(2.8) \%$ in the groups receiving $2 \mathrm{mg}, 1 \mathrm{mg}$, and $0.5 \mathrm{mg}$ ibandronate, respectively, compared with a loss of BMD of $0.4(2.4) \%$ in the women in the placebo group; $p=0.0001$ for each ibandronate dose $v$ placebo. Highest BMD gains occurred in women with osteopenia receiving $2 \mathrm{mg}$ ibandronate. Similarly, at the hip, all three doses of ibandronate produced significantly better gains in BMD than placebo $(p<0.05)$, with the greatest gains in the women with osteopenia receiving the $2 \mathrm{mg}$ dose. Ibandronate concomitantly and dose dependently suppressed markers of bone turnover in comparison with placebo, and injections were well tolerated.

Conclusion: IV ibandronate injections, given every three months, may be an effective alternative to oral bisphosphonates and hormonal therapy in the prevention of bone loss in postmenopausal women.
\end{abstract}

O steoporosis is a progressive systemic disease that causes the skeleton to become susceptible to fractures. ${ }^{2}$ As osteoporotic fractures are associated with significant morbidity and mortality, ${ }^{4}$ this disease has important implications for public health. ${ }^{5}$ Consequently, its prevention might be of considerable socioeconomic benefit.

The risk-benefit profile from the use of combined oestrogen plus progestin among healthy postmenopausal women is not consistent with the requirements for primary prevention of chronic diseases. ${ }^{6}$ Thus, hormone replacement therapy is of limited value in the long term strategy to prevent or delay postmenopausal bone loss. Selective oestrogen receptor modulators are promising alternatives. ${ }^{7}$ However, additional effective, well tolerated and convenient agents to prevent postmenopausal osteoporosis would be of considerable value.

Oral bisphosphonates are widely used in the treatment of postmenopausal osteoporosis and may be important in its prevention. $^{8-11}$ However, despite their proven efficacy, conventional daily bisphosphonates must be given in accordance with stringent dosing recommendations. ${ }^{10}{ }^{12-15}$ Depending on the frequency of dosing, these requirements may be inconvenient for some patients, with the potential to impair long term compliance and thereby jeopardise efficacy. ${ }^{16}$ To overcome these limitations, a number of alternative dosing options and schedules are being explored. ${ }^{17}$

Less frequent bisphosphonate dosing schedules increase patient convenience and are likely to have a positive impact on patients' willingness to comply with bisphosphonate administration. ${ }^{18}{ }^{19}$ Intermittent intravenous (IV) administration has the advantages of less frequent administration and, in addition, avoids the problems of reduced bioavailability and upper gastrointestinal adverse events. These benefits might promote long term compliance and so optimise patient management.

Ibandronate is a highly potent nitrogen containing bisphosphonate. Oral and IV dosing regimens of ibandronate are under investigation for both the treatment and prevention of postmenopausal osteoporosis. ${ }^{20-26}$ Trials conducted in women with postmenopausal osteoporosis, and a study in patients with corticosteroid induced osteoporosis, have shown that IV ibandronate $2 \mathrm{mg}$ injections given every three months markedly increase spinal and hip bone mineral density (BMD), and significantly suppress the rate of bone turnover. ${ }^{20}{ }^{27}$ Reassuringly, clinical trials have established that intermittent IV ibandronate injections are well tolerated. ${ }^{22-28}$ To date, however, no studies have investigated intermittent IV use of a bisphosphonate in the prevention of postmenopausal osteoporosis.

This phase II/III study, therefore, aimed at investigating the efficacy and safety of three doses $(0.5 \mathrm{mg}, 1 \mathrm{mg}$, and $2 \mathrm{mg})$ of ibandronate, given every three months by IV injection.

\section{PATIENTS AND METHODS \\ Patients}

Eligible women were postmenopausal ( $1-10$ years since last menstruation) and were recruited from centres in Norway, Russia, and the Czech Republic. Main exclusion criteria were

Abbreviations: BMD, bone mineral density; CTX, C-telopeptide; ITT intention to treat; IV, intravenous 
a mean BMD T score of the lumbar spine (Ll-4) $<-2.5$ SD; osteoporotic fracture(s); hysterectomy and/or ovariectomy; diseases, disorders, or treatment within the past six months with other drugs known to influence bone metabolism; previous treatment with bisphosphonates; fluoride treatment within the past 12 months or for a total duration of $>2$ years; any other investigational drug within 30 days of the first dose of the study drug; renal impairment (serum creatinine $>210$ $\mu \mathrm{mol} / \mathrm{l})$; contraindications to calcium treatment; hyper- or hypocalcaemia ( $\geqslant 2.6$ or $<2.0 \mathrm{mmol} / \mathrm{l}$ ).

The women were assigned to one of four strata according to their lumbar spine BMD T score at baseline, and their time since menopause: $(\mathrm{A})>-1$ and $1-3$ years; $(\mathrm{B}) \leqslant-1$ and $\geqslant-2.5$ and $1-3$ years; $(C)>-1$ and $>3$ years; $(D) \leqslant-1$ and $\geqslant-2.5$ and $>3$ years. The stratification for time since menopause was chosen in order to investigate specifically the transient acceleration of bone loss immediately after the menopause. Stratification for BMD at baseline was performed in order to detect any difference in the loss of bone mass in patients with osteopenia as compared with patients without.

The study was conducted in adherence to local drug regulation, guidelines on good clinical practice, and the principles of the Declaration of Helsinki. The ethics committee or institutional review board of the participating centres approved the study, and all the women provided written informed consent.

\section{Study design and interventions}

The study was multicentre, double blind, placebo controlled, stratified, and randomised, with four parallel treatment groups in each stratum. Although the study was planned to last for two years, it was stopped at 12 months because the results of the IV ibandronate pivotal phase III fracture study ${ }^{24}$ had recently become available. This showed that ibandronate $0.5 \mathrm{mg}$ and $1 \mathrm{mg}$ every three months produced a suboptimal reduction in fracture rate. However, the results from a follow up study of ibandronate IV injection given every three months ${ }^{27}$ proved the greater efficacy of a higher $2 \mathrm{mg}$ dose, as used in the present study.

Within each of the four strata, the women were randomly allocated to four parallel treatment groups to receive either placebo or ibandronate at a dose of $0.5 \mathrm{mg}, 1.0 \mathrm{mg}$, or $2.0 \mathrm{mg}$ given as IV injections every three months. All women received $500 \mathrm{mg}$ oral calcium supplements daily.

The women underwent a screening visit not more than one month before randomisation. Eligible women were randomised and treatment was dispensed at the start of the study when baseline information, including BMD, was collected. Subsequent visits took place at one week, and at months 1, 2, 3, 6, 9, and 12. In addition to the screening and baseline visits, BMD was measured at months 6 and 12. Laboratory assessments for safety (haematology; serum electrolyte concentrations; measures of hepatic and renal function; 25-hydroxyvitamin D) were done on blood and serum samples at baseline, and at months 3, 6, and 12. Measurements of biochemical markers of bone turnover were scheduled at baseline and each subsequent visit at selected centres.

\section{BMD measurements}

BMD measurements were performed using dual energy $x$ ray absorptiometry (Hologic QDR 2000 and 4500) at the lumbar spine (Ll-4) and the proximal femur (total hip, femoral neck, and trochanter).

\section{Biochemical markers of bone turnover}

Serum and urine samples for the measurement of biochemical markers of bone turnover (urinary C-telopeptide of the $\alpha$ chain of type I collagen (CTX/creatinine) and serum C-telopeptide (CTX), bone-specific alkaline phosphatase, osteocalcin, and parathyroid hormone) were collected only at the participating centres in Norway and were analysed centrally by SYNARC, Ballerup, Denmark to maintain blinding. Urinary CTX/creatinine was analysed with the Crosslaps (Osteometer) kit; serum CTX and serum osteocalcin were analysed by Elecsys immunoassays (Roche Diagnostics). The blood samples collected at baseline and on all follow up visits were taken at a similar time of day. Urine samples were collected from the second morning spot urine.

As serum and urine samples were only obtained just before the next drug administration, the measurements of biochemical markers of bone turnover represent residual levels of bone turnover suppression. Data are, therefore, not available on the reductions in bone turnover immediately after each injection.

\section{Study outcomes}

The primary efficacy end point was the relative change from baseline in the BMD of the lumbar spine (Ll-4) after treatment for one year (changed from the original two years when the study was ended). Secondary efficacy end points were the absolute and relative changes in BMD at the proximal femur (total hip, femoral neck, and trochanter); the change from baseline in rate of bone turnover as shown by the biochemical markers of bone turnover listed above.

Safety end points comprised adverse events; parameters of renal and hepatic function; other laboratory measures, including haematology and serum electrolyte concentrations.

\section{Sample size}

It was planned to recruit a total of 600 patients into this trial, with 150 patients in each treatment group (see fig 1 for actual patient recruitment size). This level of recruitment accounted for an expected drop-out rate of about $9 \%$ a year, resulting in an evaluable sample size of 112 patients in each treatment group after two years of study.

To enable a more precise estimation of the treatment effects in osteopenic women, the number of patients to be recruited in strata B and D was twice that in strata A and C. For each treatment group, the following sample size for each stratum was planned:

- Stratum A: 25 randomised patients (17 evaluable after two years)

- Stratum B: 50 randomised patients (39 evaluable after two years)

- Stratum C: 25 randomised patients (17 evaluable after two years)

- Stratum D: 50 randomised patients (39 evaluable after two years).

In a previous study an increase in lumbar spine BMD of about 4 (SD 3.5)\% was observed after one year's treatment with ibandronate. ${ }^{20}$ Based on these results, it was expected that the planned strata sample sizes used in our study would allow for clinically significant changes in lumbar spine BMD of 3\% relative to placebo after two years of treatment. For strata B and D, a $4 \%$ standard deviation of the change in BMD was assumed $(\alpha=5 \%$ and $\beta=10 \%$ ). For strata $A$ and $C$, the assumption was made of a $3 \%$ standard deviation of the change $(\alpha=5 \%$ and $\beta=20 \%$ ).

\section{Blinding}

The investigators, the patients, and the sponsor personnel were all unaware of which treatment was being received. Laboratory parameters were measured centrally and, with the exception of baseline values, no efficacy laboratory data were shown to the investigator. BMD measurements were also analysed centrally. Data collected after the first administration of study drug were not shown to the investigator, other clinic staff, or patients, unless the loss of BMD reached the predefined safety threshold. Women whose BMD during the first year decreased by $>8 \%$ (as confirmed by two measurements three months apart) were offered alternative active 


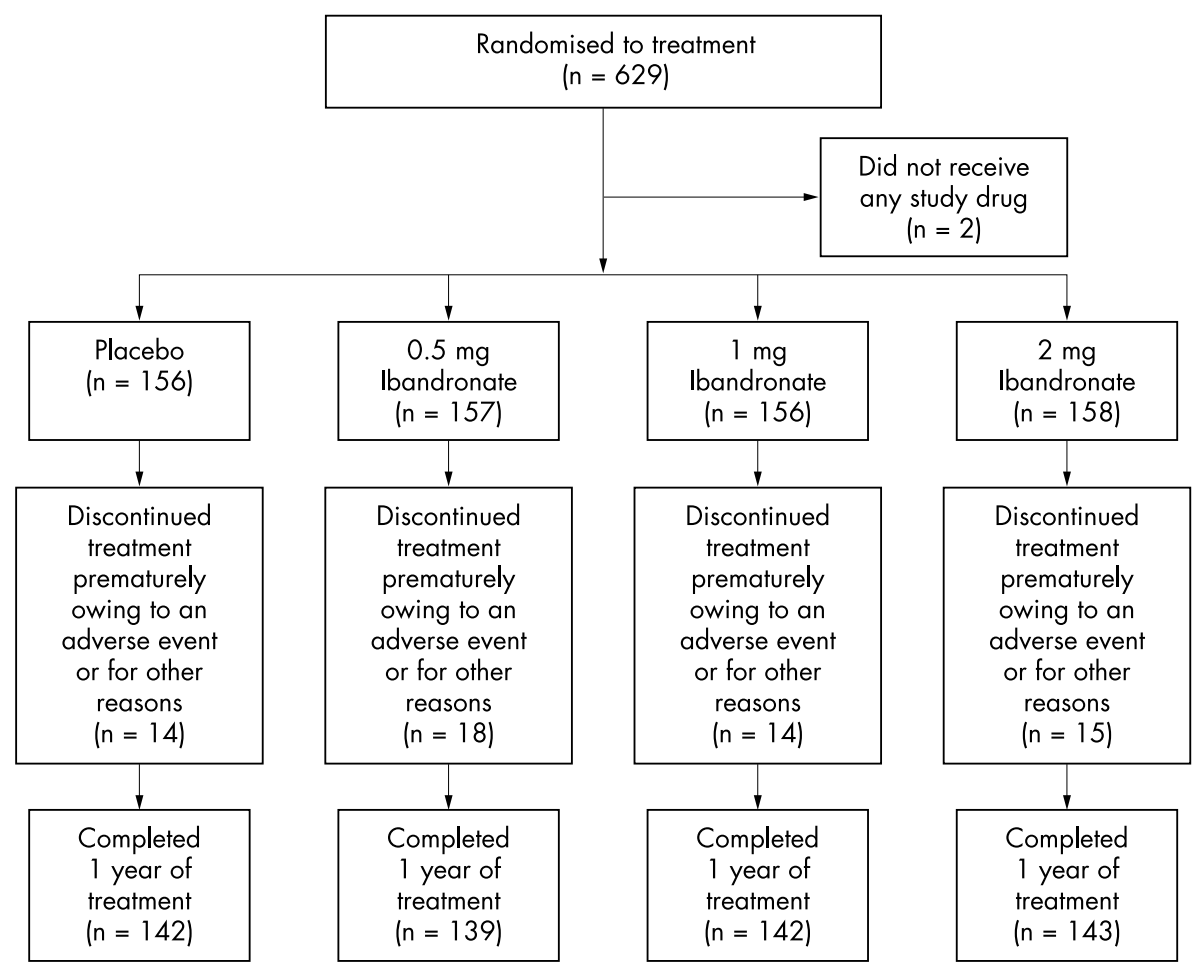

Figure 1 Patient grouping.

treatment for osteoporosis but were encouraged to stay in the study. Women with symptomatic and radiologically confirmed vertebral fractures were withdrawn from the study.

The treatment code for an individual patient was not to be broken during the trial, unless a serious adverse event occurred for which information about the trial drug was needed for medical management.

\section{Statistical methods}

The safety group comprised all randomised patients who had received at least one dose of the study drug. The intention to treat (ITT) population was used for the primary efficacy analysis and included all the patients in the safety group for whom the lumbar spine BMD was measured and evaluable at baseline and at least at one follow up visit. The primary efficacy analysis-that is, analysis of the relative change from baseline in lumbar spine BMD after one year of treatment, followed a set of partial and ordered predefined hypotheses so that the difference in the relative change in lumbar spine BMD after one year between the treatment groups at the same $\alpha$ level of 0.05 could be investigated. The hypotheses postulated that this relative change did not differ between: $(a)$ the placebo and ibandronate $2.0 \mathrm{mg}$ group; $(b)$ the placebo and the ibandronate $1.0 \mathrm{mg}$ group; (c) the placebo and the ibandronate $0.5 \mathrm{mg}$ group. It was expected that these null hypotheses would be rejected. The hypotheses were tested by analysis of variance, with treatment group and stratum as independent variables. The primary analysis of the change in lumbar spine BMD used the last value carried forward method for the one year treatment period. The BMD of all other sites was analysed as for the primary variable.

For biochemical markers of bone turnover, differences in relative change from baseline between treatment groups and placebo were not expected to be normally distributed and, therefore, were tested using Wilcoxon's rank sum test.

\section{RESULTS}

Patient disposition and baseline characteristics

Figure 1 summarises the overall patient grouping. A total of 629 women were randomly allocated to take part in the study, which took place between May 1998 and May 2000. Two women (one each in the placebo and $2.0 \mathrm{mg}$ ibandronate group) received no study drug; thus 156, 157, 156, and 158 women, respectively, were randomly allocated to receive placebo, $0.5 \mathrm{mg}, 1.0 \mathrm{mg}$ and $2.0 \mathrm{mg}$ IV ibandronate. All women randomised, with the exception of the two described above, received at least one dose of the assigned treatment. The safety group thus comprised 627 women. Overall, 28 women were excluded from the ITT population, most of them because of a lack of a follow up BMD measurement; the ITT population therefore comprised 601 women. Table 1 shows the patient distribution by stratum and treatment group in the ITT population.

\begin{tabular}{|c|c|c|c|c|}
\hline \multirow{2}{*}{$\begin{array}{l}\text { Stratum (T score; time since } \\
\text { menopause) }\end{array}$} & \multirow[b]{2}{*}{ Placebo (n) } & \multicolumn{3}{|c|}{ Intravenous ibandronate } \\
\hline & & $0.5 \mathrm{mg}(\mathrm{n})$ & $1.0 \mathrm{mg}(\mathrm{n})$ & $2.0 \mathrm{mg}(\mathrm{n})$ \\
\hline A (>-1; $1-3$ years) & 22 & 24 & 25 & 26 \\
\hline $\mathrm{B}(\leqslant-1, \geqslant-2.5 ; 1-3$ years $)$ & 48 & 50 & 49 & 50 \\
\hline$C(>-1 ;>3$ years $)$ & 24 & 26 & 27 & 25 \\
\hline $\mathrm{D}(\leqslant-1, \geqslant-2.5 ;>3$ years $)$ & 53 & 51 & 51 & 50 \\
\hline
\end{tabular}


Table 2 Demographic characteristics at baseline - safety group (mean (SD))

\begin{tabular}{lllll}
\hline & \multicolumn{4}{l}{ Intravenous ibandronate } \\
\cline { 3 - 5 } & $\begin{array}{l}\text { Placebo } \\
(\mathrm{n}=156)\end{array}$ & $\begin{array}{l}0.5 \mathrm{mg} \\
(\mathrm{n}=157)\end{array}$ & $\begin{array}{l}1.0 \mathrm{mg} \\
(\mathrm{n}=156)\end{array}$ & $\begin{array}{l}2.0 \mathrm{mg} \\
(\mathrm{n}=158)\end{array}$ \\
\hline Age & $54.6(3.5)$ & $54.7(3.3)$ & $54.9(2.9)$ & $54.8(3.2)$ \\
Time since menopause (years) & $4.1(2.4)$ & $4.3(2.7)$ & $4.3(2.6)$ & $4.3(2.6)$ \\
Height $(\mathrm{cm})$ & $164.9(5.9)$ & $164.8(5.6)$ & $164.4(5.9)$ & $164.6(6.0)$ \\
Weight $(\mathrm{kg})$ & $73.4(12.9)$ & $70.8(11.8)$ & $71.4(11.0)$ & $71.3(12.1)$ \\
25-hydroxyvitamin D at baseline $(\mathrm{ng} / \mathrm{ml})$ & $37.4(13.4)$ & $37.7(11.4)$ & $38.1(11.9)$ & $37.4(10.7)$ \\
BMD T score at baseline & $-1.2(0.9)$ & $-1.1(0.9)$ & $-1.1(1.0)$ & $-1.2(0.9)$ \\
\hline & & & & \\
\hline
\end{tabular}

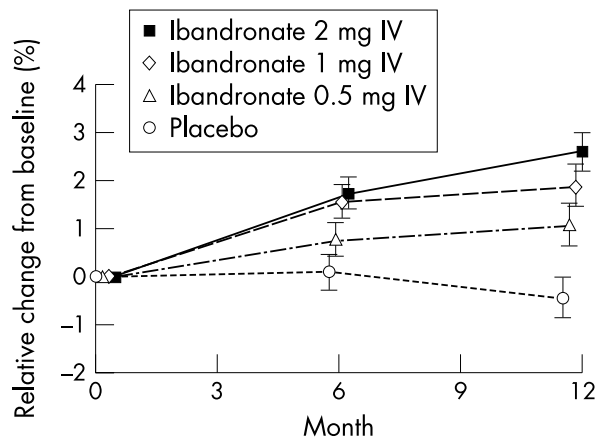

Figure 2 Relative percentage change from baseline in BMD at the lumbar spine (L 1-4) in the ITT population.

Baseline demographic characteristics, including age, height, weight, time since menopause, BMD $\mathrm{T}$ score and 25-hydroxyvitamin D levels were well balanced between treatment groups (table 2), as were biochemical markers of bone turnover. There were no significant differences in previous or current medical history, physical activity, or diet between the groups (data not shown).

\section{Efficacy}

\section{BMD}

After one year, IV injections of $0.5 \mathrm{mg}, 1 \mathrm{mg}$, and $2 \mathrm{mg}$ ibandronate given every three months produced dose dependent increases in mean (SD) lumbar spine BMD of $1.0(2.8) \%, 1.8$ $(2.6) \%$, and $2.5(2.5) \%$, respectively, relative to baseline (fig 2 ). In contrast, mean lumbar spine BMD decreased in the placebo group $(-0.4 \%(2.4) \%)$, relative to baseline. Notably, all three ibandronate treatment groups produced significantly greater gains in lumbar spine BMD than placebo after 12 months $(p \leqslant 0.0001)$.

This study was not powered to analyse significance within the strata. Nevertheless, for each stratum, the increase in lumbar spine BMD in all three ibandronate groups was significant $(p<0.05)$ relative to placebo, with the exception of stratum A ( $p<0.05$ only for $2 \mathrm{mg})$ and B ( $<<0.05$ only for $1 \mathrm{mg}$ and $2 \mathrm{mg}$ ) (table 3 ). The greatest increases in lumbar spine
BMD were seen in the osteopenic patients in strata B and D treated with $2 \mathrm{mg}$ ibandronate (table 3 ). The mean increase in BMD in these two groups was $3.5 \%$ and $3.1 \%$, respectively, relative to placebo.

In the total hip and its subregions, changes in BMD were significantly $(p<0.05)$ greater for all ibandronate treatment groups than for the placebo group, after 12 months. BMD of patients in the placebo group decreased in all the subregions analysed (table 4). Of the three doses of ibandronate, $2 \mathrm{mg}$ had the most marked effect after one year, producing BMD increases of $1.7 \%, 0.9 \%$, and $2.1 \%$ at the total hip, femoral neck, and trochanter, respectively. Overall, the largest increases in BMD at the total hip and its subregions were seen in osteopenic patients (strata B and D) treated with $2 \mathrm{mg}$ ibandronate (table 5 ).

\section{Biochemical markers of bone turnover}

Consistent with its significant effect on spinal and hip BMD, ibandronate produced sustained reductions in biochemical markers of bone turnover. Ibandronate was associated with dose dependent suppression of biochemical markers of bone resorption (serum CTX and urinary CTX/creatinine) throughout the 12 months' treatment (figs $3 \mathrm{~A}$ and $\mathrm{B}$ ). The two highest doses of ibandronate ( $1 \mathrm{mg}$ and $2 \mathrm{mg}$ ) produced significantly $(\mathrm{p}<0.05)$ greater reductions in serum CTX and urinary CTX/creatinine levels versus placebo, after 12 months. Serum CTX and urine CTX/creatinine levels were reduced by $42 \%$ and $50 \%$, respectively, for patients treated with $2 \mathrm{mg}$ ibandronate, compared with $9 \%$ and $7 \%$ for patients receiving placebo, after one year. The decrease in serum CTX was not significantly different across the four strata. However, urinary CTX/creatinine levels declined most markedly in osteopenic patients receiving the $2 \mathrm{mg}$ dose of ibandronate (by 52\% and $53 \%$ in strata B and D, respectively; data not shown).

Median serum levels of biochemical markers of bone formation (bone-specific alkaline phosphatase and osteocalcin (fig 3C) were also decreased in a dose dependent manner over the 12 months, with all three doses of ibandronate producing significantly greater suppression than placebo $(\mathrm{p}<0.05)$. IV ibandronate $2 \mathrm{mg}$ injections were associated with reductions of $13 \%$ and $38 \%$, respectively, in bone-specific

Table 3 Summary of the mean $(95 \% \mathrm{Cl})$ change (\%) in lumbar spine (L1-4) BMD in the four strata after 12 months, relative to baseline (last value carried forward) in the ITT population

\begin{tabular}{lllllll}
\hline & & \multicolumn{3}{l}{ Intravenous ibandronate } \\
\cline { 2 - 6 } $\begin{array}{l}\text { Stratum (T score; time } \\
\text { since menopause) }\end{array}$ & Placebo & $0.5 \mathrm{mg}$ & $1.0 \mathrm{mg}$ & $2.0 \mathrm{mg}$ \\
\hline $\mathrm{A}(>-1 ; 1-3$ years) & $-0.0(-1.1$ to 1.1$)$ & $1.1(-0.2$ to 2.4$)$ & $1.1(-0.0$ to 2.2$)$ & $1.8(0.7 \text { to } 2.8)^{*}$ \\
$\mathrm{~B}(\leqslant-1, \geqslant-2.5 ; 1-3$ years) & $-0.7(-1.4$ to -0.1$)$ & $0.4(-0.4$ to 1.2$)$ & 1.9 & $(1.1 \text { to } 2.6)^{*}$ & $2.8(2.1 \text { to } 3.5)^{*}$ \\
$\mathrm{C}(>-1 ;>3$ years $)$ & $-0.4(-1.3$ to 0.6$)$ & $1.4(0.5 \text { to } 2.2)^{*}$ & $1.9(1.2 \text { to } 2.5)^{*}$ & $1.9(1.0 \text { to } 2.8)^{*}$ \\
$\mathrm{D}(\leqslant-1, \geqslant-2.5 ;>3$ years) & $-0.2(-0.9$ to 0.5$)$ & $1.4(0.7 \text { to } 2.1)^{*}$ & $2.2(1.4 \text { to } 3.0)^{*}$ & $2.9(2.2 \text { to } 3.5)^{*}$ \\
\hline
\end{tabular}


Table 4 Summary of the mean $(95 \% \mathrm{Cl})$ change $(\%)$ in proximal femur BMD after 12 months, relative to baseline (last value carried forward) in the ITT population

\begin{tabular}{lllll}
\hline & & \multicolumn{3}{l}{ Intravenous ibandronate } \\
\cline { 2 - 5 } Hip area & Placebo & $0.5 \mathrm{mg}$ & $1.0 \mathrm{mg}$ & $2.0 \mathrm{mg}$ \\
\hline Total hip & $-0.2(-0.5$ to 0.1$)$ & $0.8(0.5 \text { to } 1.2)^{*}$ & $1.1(0.8 \text { to } 1.4)^{*}$ & $1.7(1.4 \text { to } 2.0)^{*}$ \\
Femoral neck & $-0.8(-1.3$ to -0.3$)$ & $0.3(-0.3$ to 0.9$) *$ & $0.2(-0.3$ to 0.7$)$ * & $0.9(0.4 \text { to } 1.5)^{*}$ \\
Trochanter & $-0.3(-0.7$ to 0.1$)$ & $1.4(0.9 \text { to } 1.9)^{*}$ & $1.7(1.3$ to 2.1$) *$ & $2.1(1.7 \text { to } 2.5)^{*}$ \\
\hline * Difference between active group and placebo was significant $(\mathrm{p}<0.05)$. &
\end{tabular}

Table 5 Summary of the mean $(95 \% \mathrm{Cl})$ change $(\%)$ in proximal femur BMD in the four strata after 12 months, relative to baseline (last value carried forward) in the ITT population

\begin{tabular}{|c|c|c|c|c|}
\hline \multirow{2}{*}{$\begin{array}{l}\text { Hip area and stratum (T score; time } \\
\text { since menopause) }\end{array}$} & \multirow[b]{2}{*}{ Placebo } & \multicolumn{3}{|c|}{ Intravenous ibandronate } \\
\hline & & $0.5 \mathrm{mg}$ & $1.0 \mathrm{mg}$ & $2.0 \mathrm{mg}$ \\
\hline \multicolumn{5}{|l|}{ Total hip } \\
\hline $\mathrm{A}(>-1 ; 1-3$ years $)$ & $0.4(-0.5$ to 1.3$)$ & $0.3(-0.5$ to 1.1$)$ & $0.5(-0.2$ to 1.2$)$ & $1.0(0.4$ to 1.6$)$ \\
\hline $\mathrm{B}(\leqslant-1, \geqslant-2.5 ; 1-3$ years $)$ & $-0.3(-1.0$ to 0.3$)$ & $0.6(0.1 \text { to } 1.1)^{*}$ & $1.1(0.5 \text { to } 1.6)^{*}$ & $1.9(1.3$ to 2.5$)$ * \\
\hline$C(>-1 ;>3$ years $)$ & $-0.4(-1.1$ to 0.3$)$ & $1.5(0.6 \text { to } 2.5)^{*}$ & $1.1(0.2 \text { to } 2.0)^{*}$ & $1.5(0.8 \text { to } 2.3)^{*}$ \\
\hline $\mathrm{D}(\leqslant-1, \geqslant-2.5 ;>3$ years $)$ & $-0.3(-0.8$ to 0.2$)$ & $1.0(0.4 \text { to } 1.5)^{*}$ & $1.4(0.9 \text { to } 2.0)^{*}$ & $1.9(1.3$ to 2.5$)$ * \\
\hline \multicolumn{5}{|l|}{ Femoral neck } \\
\hline $\mathrm{A}(>-1 ; 1-3$ years) & $-0.4(-2.2$ to 1.5$)$ & $-0.1(-1.5$ to 1.3$)$ & $-0.6(-1.6$ to 0.4$)$ & $0.2(-1.4$ to 1.8$)$ \\
\hline$B(\leqslant-1, \geqslant-2.5 ; 1-3$ years $)$ & $-0.9(-1.8$ to 0.0$)$ & $-0.1(-1.0$ to 0.8$)$ & $0.4(-0.6 \text { to } 1.3)^{*}$ & $1.1(0.2 \text { to } 1.9)^{*}$ \\
\hline$C(>-1 ;>3$ years $)$ & $-0.7(-1.7$ to 0.4$)$ & $0.2(-1.1$ to 1.5$)$ & $0.8(-0.5$ to 2.1$)$ & $1.0(-0.2$ to 2.1$)$ \\
\hline$D(\leqslant-1, \geqslant-2.5 ;>3$ years $)$ & $-1.0(-1.9$ to -0.1$)$ & $0.9(-0.3 \text { to } 2.2)^{*}$ & $0.2(-0.8 \text { to } 1.1)^{*}$ & $1.1(0.2 \text { to } 2.1)^{*}$ \\
\hline \multicolumn{5}{|l|}{ Trochanter } \\
\hline $\mathrm{A}(>-1 ; 1-3$ years $)$ & $0.4(-0.9$ to 1.6$)$ & $1.1(-0.2$ to 2.3$)$ & $1.2(0.1$ to 2.3$)$ & $1.4(0.3$ to 2.6$)$ \\
\hline $\mathrm{B}(\leqslant-1, \geqslant-2.5 ; 1-3$ years $)$ & $0.1(-0.7$ to 0.8$)$ & $0.9(0.1$ to 1.8$)$ & $1.6(0.9 \text { to } 2.3)^{*}$ & $2.4(1.7$ to 3.1$)$ * \\
\hline$C(>-1 ;>3$ years $)$ & $-0.6(-1.6$ to 0.5$)$ & $1.6(0.2 \text { to } 3.0)^{*}$ & $1.8(0.7 \text { to } 3.0)^{*}$ & $1.4(0.6 \text { to } 2.2)^{*}$ \\
\hline$D(\leqslant-1, \geqslant-2.5 ;>3$ years $)$ & $-0.7(-1.3$ to -0.1$)$ & $1.8(1.1 \text { to } 2.6)^{*}$ & $2.0(1.3$ to 2.7$)$ * & $2.4(1.7$ to 3.1$)$ * \\
\hline
\end{tabular}

alkaline phosphatase and osteocalcin levels; the corresponding reductions for placebo were $2 \%$ and $8 \%$, respectively. In all four strata, the most pronounced effects were seen in the $1 \mathrm{mg}$ and $2 \mathrm{mg}$ groups (data not shown).

No significant changes in serum parathyroid hormone levels were seen in the ibandronate groups in comparison with placebo, and no relevant or dose dependent changes in these concentrations were seen across the four strata.

\section{Safety}

Ibandronate was well tolerated, with an incidence of adverse events similar to placebo: $75 \%$ of patients in the placebo group, and $82-84 \%$ in the ibandronate groups had at least one adverse event. Similarly, there were no marked differences in the type or incidence of adverse events between treatment groups with the exception of myalgia, which was reported in $22(14 \%), 18(12 \%)$, and $34(22 \%)$ of the patients in the ibandronate $0.5 \mathrm{mg}, 1 \mathrm{mg}$, and $2 \mathrm{mg}$ groups, respectively, and in 7 (4\%) of those in the placebo group. The myalgia, which was generally self limiting, reversible, and occurred mainly after the first injection, accounted for the higher proportion of patients treated with ibandronate experiencing drug related adverse events: 19 (12\%) in the placebo group versus 48 (30\%) of those receiving the highest dose of ibandronate. Myalgia led to withdrawal of $3(1.9 \%), 1(0.6 \%)$, and $4(2.5 \%)$ women in the $0.5 \mathrm{mg}, 1 \mathrm{mg}$, and $2 \mathrm{mg}$ ibandronate groups, respectively; no woman in the placebo group withdrew owing to myalgia.

Only one woman (in the $1 \mathrm{mg}$ ibandronate group) had a serious adverse event that was considered drug related. She had a history of recurrent muscle pain and was withdrawn from the study because of musculoskeletal chest pain, which resolved within four days after the drug was stopped.

No clinically significant changes in laboratory parameters, including those of renal function, were seen during the study in any of the treatment groups.

\section{DISCUSSION}

Although hormone replacement therapy, selective oestrogen receptor modulators, and oral daily bisphosphonates have been registered for the prevention of postmenopausal osteoporosis, their potential limitations indicate a need for alternative forms of pharmacological treatment. In this study, one year of treatment with ibandronate at a dose of $0.5,1.0$, or $2.0 \mathrm{mg}$ given intermittently as an IV injection every three months produced significant and dose dependent increases in the BMD of the lumbar spine, and the total hip and its subregions. The gains in BMD were accompanied by dose related and sustained suppression of biochemical markers of bone resorption (serum CTX and urinary CTX/creatinine) and bone formation (serum osteocalcin and bone-specific alkaline phosphatase).

Of the doses of intermittent IV ibandronate studied, $2 \mathrm{mg}$ was the most effective in preventing bone loss, producing mean BMD gains of $2.5 \%$ in the lumbar spine and $1.7 \%$ in the total hip. This dose was also the most efficacious in normalising bone turnover. Although there are limitations in comparing results from different clinical trials, it is notable that the effect of $2 \mathrm{mg}$ ibandronate injections on BMD is comparable with the effect seen with other nitrogen containing bisphosphonates, such as alendronate and risedronate, given orally every day to postmenopausal women who did not have osteoporosis. ${ }^{11} 29$ After one year of treatment, oral daily alendronate $\left(5 \mathrm{mg}^{11}\right)$ and oral daily risedronate $\left(5 \mathrm{mg}^{29}\right)$ produced respective mean lumbar spine BMD increases of $2.7 \%$ and $1.3 \%$, relative to baseline, in postmenopausal women without osteoporosis.

The protective effects of ibandronate were seen regardless of $\mathrm{BMD}$ at baseline and time since menopause. However, the effect of intermittent IV ibandronate injections was most evident in osteopenic women, as shown by a more pronounced increase in mean BMD at the various sites studied, and a greater suppression of the biochemical markers of bone turnover compared with the non-osteopenic patients. 

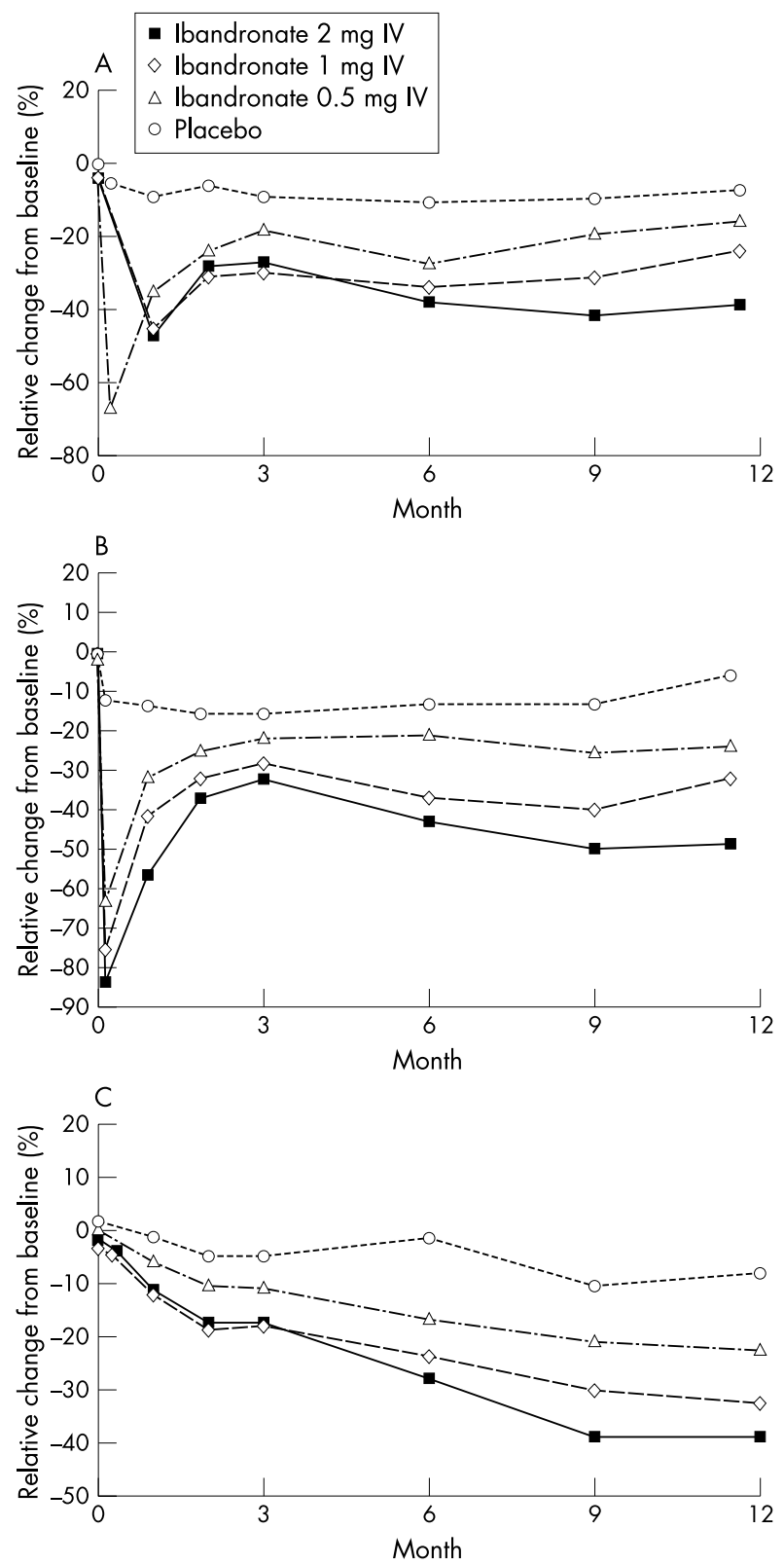

Figure 3 Relative percentage change from baseline in (A) serum CTX, (B) urinary CTX/creatinine, and (C) serum osteocalcin levels in the ITT population.

The IV administration of ibandronate was well tolerated at all the doses tested. There were no marked differences in the type or incidence of adverse events between treatment groups, with the exception of myalgia. However, myalgia is a recognised non-specific, early, adverse event of other nitrogen containing bisphosphonates, such as alendronate and zoledronate, when given intravenously, ${ }^{30}{ }^{31}$ and in this study was generally mild, self limiting, and transient. Although myalgia was reported in this study, it is notable that no apparent symptomatic acute phase reaction events were observed in association with IV ibandronate.

In conclusion, this is the first study demonstrating the efficacy and tolerability of intermittent IV injections of a bisphosphonate in preventing bone loss in early postmenopausal women. Intermittent IV ibandronate injections offer the promise of an effective and convenient alternative to oral selective oestrogen receptor modulators and oestrogen replacement therapy for this indication.

\section{ACKNOWLEDGEMENTS}

We thank Rolf Meinert (Germany) for assisting with the statistical analyses and Lillia Fries (Norway), Ine Kleppestø (Norway), Jana Krenkova (Czech Republic), Gro Skjæveland (Norway), Barbora Stulcova (Czech Republic), Eva Ticha (Czech Republic), and Natalia Toroptsova (Russia) for their significant contribution to the study.

This trial was sponsored by F Hoffmann-La Roche Ltd, Basel, Switzerland.

\section{Authors' affiliations}

J A Stakkestad, CECOR AS, Haugesund, Norway

L I Benevolenskaya, Institute of Rheumatology, Moscow, Russia

J J Stepan, Charles University Faculty of Medicine, Prague, Czech Republic

A Skag, E Oefjord, Centre for Clinical Trials, Paradis, Norway

A Nordby, Sentrum Røntgen Institutt, Trondheim, Norway

A Burdeska, I Jonkanski, P Mahoney, F Hoffmann-La Roche Ltd, Basel, Switzerland

\section{REFERENCES}

1 Riggs BL, Melton L III. The prevention and treatment of osteoporosis. N Engl J Med 1992;327:620-7. (Erratum: N Engl J Med 1993;328:65).

2 Black DM, Cummings SR, Melton LV III. Appendicular bone mineral and a woman's lifetime risk of hip fractures. J Bone Miner Res 1992:7:639-46.

3 Kanis JA, Delmas P, Burckhardt P, Cooper C, Torgerson D. Guidelines for diagnosis and management of osteoporosis. Osteoporos Int 1997;7:390-406

4 Cummings SR, Melton L. Epidemiology and outcomes of osteoporotic fractures. Lancet 2002:359:1761-7.

5 Barret-Connor E. The economic and human costs of osteoporotic fracture. Am J Med 1995;98(suppl 2a):3-8S.

6 Women's Health Initiative Investigators. Risks and benefits of estrogen plus progestin in healthy postmenopausal women: principal results from the Women's Health Initiative randomized controlled trial. JAMA 2002:288:321-33.

7 Ettinger B, Black DM, Mitlak BH, Knickerbocker RK, Nickelsen T, Genant HK, et al. Reduction of vertebral fracture risk in postmenopausal women with osteoporosis treated with raloxifene: results from a 3-year randomized clinical trial. Multiple Outcomes of Raloxifene Evaluation (MORE) Investigators. JAMA 1999;282:637-45.

8 Russell RGG, Croucher PL, Rogers M. Bisphosphonates: pharmacology, mechanisms of action and clinical uses. Osteoporos Int 1999;9/suppl 2):S66-80.

9 Gatti D, Adami S. New bisphosphonates in the treatment of bone diseases. Drugs Aging 1999;15:285-96.

10 Papapoulos SE. Bisphosphonates in the management of postmenopausal osteoporosis. In: Marcus R, Feldman D, Kelsey J, eds. Osteoporosis. Vol 2. 2nd ed. New York: Academic Press, 2001:631-49.

11 Hosking D, Chilvers CE, Christiansen C, Ravn P, Wasnich R, Ross P, et al. Prevention of bone loss with alendronate in postmenopausal women under 60 years of age. Early Postmenopausal Intervention Cohort Study Group. N Engl J Med 1998;338:485-92.

12 Fleisch $\mathbf{H}$. Bisphosphonates: pharmacology and use in the treatment of tumor-induced hypercalcaemia and metastatic bone disease. Drugs 1991;42:919-44.

13 Gertz BJ, Holland SD, Kline WF, Matuszewski, Porras AG. Clinical pharmacology of alendronate sodium. Osteoporosis Int 1993;3/suppl 3): S13-16.

14 Adami S, Zamberlan N. Adverse effects of bisphosphonates. A comparative review. Drug Safety 1996;14:158-70.

15 Body J-J. Dosing regimens and main adverse events of bisphosphonates. Semin Oncol 2001;28(suppl 11):49-53.

16 Caro J, Huybrechts K, Ishak K, Naujoks C. The impact of adherence to osteoporosis therapy on fracture rates in actual practice. Value in Health 2002;5:127.

17 Schnitzer T, Bone HG, Crepaldi G, Adami S, McClung M, Kiel D, et al. Therapeutic equivalence of alendronate $70 \mathrm{mg}$ once-weekly and alendronate $10 \mathrm{mg}$ daily in the treatment of osteoporosis. Alendronate Once-Weekly Study Group. Aging (Milano) 2000;12:1-12

18 Kendler DL, Diez-Perez A, Gaines KA, Verbruggen N, Melton ME. Patient preference of once weekly or daily administration of alendronate (Fosamax) for osteoporosis: a randomized cross-over study [abstract]. Osteoporos Int 2002;13(suppl 1):S32.

19 Simon JA, Lewiecki EM, Smith ME, Petruschke RA, Wang L, Palmisano JJ. Patient preference for once-weekly alendronate $70 \mathrm{mg}$ versus once-daily alendronate $10 \mathrm{mg}$ : a multicenter, randomized, open-label, crossover study. Clin Ther 2002;24:1871-86.

20 Thiébaud D, Burckhardt P, Kreigbaum H, Huss H, Mulder H, Juttmann $\mathrm{JR}$, et al. Three monthly intravenous injections of ibandronate in the treatment of postmenopausal osteoporosis. Am J Med 1997;103:298307

21 Stakkestad JA, Skag A, Nordby A, Burdeska A, Jonkanski I, Meinert R. Three-monthly intravenous ibandronate bolus injections: a novel treatmen regimen to prevent postmenopausal bone loss [abstract]. Osteoporos Int 2002;13(suppl 1):S17. 
22 Adami S, Delmas P, Felsenberg D, Christiansen C, Robinson J, Coutant $\mathrm{K}$. Three-monthly $2 \mathrm{mg}$ intravenous ibandronate bolus injections significantly increase BMD in women with postmenopausal osteoporosis [abstract]. Osteoporos Int 2002;13(suppl 1):S14.

23 Adami S, Schimmer R, Coutant K, Mahoney P. Three-monthly $2 \mathrm{mg}$ intravenous ibandronate injections restore bone turnover to premenopausal levels [abstract]. J Bone Miner Res 2002;17/suppl 1):S472

24 Recker RR, Stakkestad JA, Felsenberg D, Chesnut III CH, Christiansen C, Ettinger MP, et al. A new treatment paradigm: quarterly injections of ibandronate reduce the risk of fractures in women with postmenopausal osteoporosis (PMO): results of a 3-year trial [abstract]. Osteoporos Int 2000; 11 (suppl 2):S209

25 Ravn P, Clemmesen B, Riis BJ, Christiansen C. The effect on bone mass and bone markers of different doses of ibandronate: a new bisphosphonate for prevention and treatment of postmenopausal osteoporosis: a 1-year, randomized, double-blind, placebo-controlled, dose-finding study. Bone 1996; 19:527-33.
26 Riis BJ, Ise J, Von Stein T, Bagger Y, Christiansen C. Ibandronate: a comparison of oral daily dosing versus intermittent dosing in

postmenopausal osteoporosis. J Bone Miner Res 2001;16:1871-8.

27 Ringe JD, Dorst A, Faber H, Ibach K, Preuss J. Three-monthly ibandronate bolus injection offers favourable tolerability and sustained efficacy advantage over two years in established corticosteroid-induced osteoporosis. Rheumatology (Oxford) 2003;42:743-9.

28 Pecherstorfer $\mathbf{M}$, Ludwig H, Schlosser K, Buck S, Huss H-J, Body J-J. Administration of the bisphosphonate ibandronate (BM 21.0955$)$ by intravenous bolus injection. J Bone Miner Res 1996;1 1:587-93.

29 Mortensen L, Charles P, Bekker PJ, Digennaro J, Johnston CC Jr. Risedronate increases bone mass in an early postmenopausal population: two years of treatment plus one year of follow-up. J Clin Endocrinol Metab 1998:83:396-402.

30 Berenson JR. Zoledronic acid in cancer patients with bone metastases: results of phase I and II trials. Semin Oncol 2001;28(suppl 6):25-34.

31 Zoja N, Keck AV, Pecherstorfer M. Comparative tolerability of drug therapies for hypercalcaemia of malignancy. Drug Safety 1999;21:389-406. 